\title{
Preliminary Basic Research on the Optimization of Oil Spill Prevention and Control Design Based on Numerical Simulation Technology for Zhoushan Ma'ao Port Area
}

\author{
Junyan DONG ${ }^{\text {a,1 }}$ Zhibo TANG ${ }^{\text {a }}$, Hanbao CHEN ${ }^{\text {b }}$ \\ ${ }^{a}$ College of Ocean and Engineering Equipment, Zhejiang Ocean University, Zhoushan \\ 316022, China \\ ${ }^{b}$ Tianjin Water Transportation Engineering Research Institute, Ministry of \\ Transportation and Communications, China
}

\begin{abstract}
This paper gives a general overview of relevant studies about oil spill emergency control designs, analyzes and discusses the structure, function and main contents of these designs. Besides, the paper proposes an integrated and practical design of emergency response steps, with related process. Taking the port area of $\mathrm{Ma}$ 'ao as a case, this paper comprehensively studies the relationship between the time of rescue vessels arriving at the oil spill location and the range of the port that can be covered by these vessels as well as the protection facilities required for the relevant shoreline.
\end{abstract}

Keywords. Oil Spill, prevention and control, optimization

\section{Introduction}

China owns 18,000 kilometers of mainland coastline and many islands, especially Zhoushan Islands, the largest archipelago in China, with nearly 1,390 islands of various sizes and a long coastline. Therefore, water transportation plays a key role in the economic development of Zhoushan [1]. In 2006, 160,000 oil tankers sailed in China's coastal waters, with an average of more than 400 vessels per day. With the implementation of China's strategic oil storage plan, more foreign tankers will join in, making the busy marine navigation environment more complex, which rises the potential for large-scale oil spill pollution caused by marine traffic accidents. Improperly handled oil spills probably cause environmental hazards and economic losses. The tanker "SANCHI" collided with other cargo ship in the East China Sea in 2018. Although most of its condensate (various low-density and low-viscosity liquid hydrocarbons) evaporated and burned before the "SANCHI" tanker sank, approximately 2,000 tons of fuel remained in the wreck, putting the local ecology and

\footnotetext{
${ }^{1}$ Junyan Dong, College of Ocean and Engineering Equipment, Zhejiang Ocean University, Zhoushan 316022, China; E-mail: 2904736384@qq.com
} 
communities at risk. The collision caused damage to one of the cargo tanks of the tanker, resulting in a spill of about 400 tons of oil into the sea. Therefore, how to deal with the oil spill in the first time is particularly important.

Chinese government's mechanism for coordinating emergency response to marine pollution incidents is relatively limited. When a marine pollution incident occurs, it often needs to rely on the vertical coordination: relying on the hierarchy, subordination and power sequence of the government to deal with the emergency; at the same time, it also needs horizontal coordination. Although there are joint meetings of various departments, emergency command and other inter-departmental work coordination mechanisms, in many cases, emergency response to the incident shows that the local government's or its departments' cooperation is not well carried out. Because of the relatively weak foundation and the current limited capital investment in China, there is an urgent need to improve the number of professional teams, the qualifed workers and the advanced technology for oil spill treatment.

\section{Oil Spill System Establishment}

Based on the relevant literature, the following is a summary of the relevant studies regarding the establishment of oil spill system.

\subsection{OSR Decision Support Technology (Multi-criteria Decision Making)}

OSR is a complex interdisciplinary field built upon environmental management, covering remote sensing, numerical simulation, operations research, GIS, and the like. The success of OSR relies on a comprehensive understanding of oil spills and related environmental processes, which has led to an increased demand for interdisciplinary and computational model development. It is a multi-criteria decision support technology [2].

\subsection{Bayesian Networks}

Bayesian networks are suitable for facilitating the reassessment and revalidation of contingency plans following a contaminant release, thus helping to ensure that optimal response strategies are employed. This minimizes the possibility of suboptimal response strategies causing additional environmental and socioeconomic damage beyond the original contamination event [3].

\subsection{Artificial Neural Networks}

Monte Carlo simulations have been used to filter/rank the available technologies for offshore oil spill cleanup based on the specifics of the oil spill site using an integrated rule-based fuzzy adaptive resonance theory mapping approach (MC-IRFAM); and a dynamic mixed integer nonlinear planning approach based on Monte Carlo simulations for multi-stage dynamic planning based on simulated oil weathering and extraction as well as dynamic optimization of technology combinations and resource allocation in each planning strategy. 
Based on these studies, the following is a newly established system based on the integration of relevant artificial neural networks. It uses a database as a platform for the whole system. In the "research support" and "mainline" modules, it applied the relevant neural network knowledge of Monte Carlo.

The following process system uses "database", "research support", "equipment library", and "actual response" as the four parts of basic modules, Fig.1, each of which may be independent and at the same time each of which may be related in operation to form a new oil spill system construction and conception.

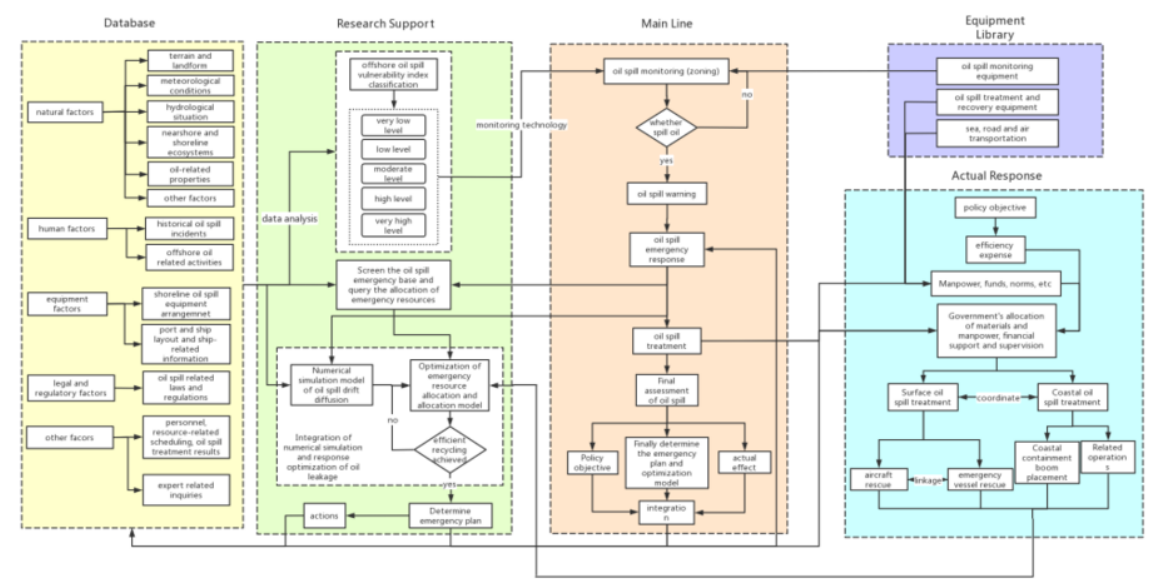

Figure 1. Oil spill treatment process chart.

The process in figure 1 uses data as the underlying platform and can be coconstructed by scientists, responders, and others. Four modules can be modified independently.

The "research support" and "mainline modules" in the process (figure 1) are built based on a two-stage adaptive resonance theory mapping approach for Monte Carlo simulations. Simulations of oil weathering and recovery are performed in each trial of the Monte Carlo simulation based on the uncertainty of the field conditions. The simulation results, randomized operating parameters and resources/constraints (e.g., manpower, financial and regulatory) form the constraints of the simulation-based optimization model. Based on this model, a simulation-based optimization method is then generated and solved for a trial until a predetermined number of trials is reached. Finally, a series of decision alternatives are generated based on the optimization results. The decision alternatives may include the technology mix (e.g., type and number of equipment), the allocation of human and financial resources, the corresponding costs and environmental impacts, etc [4].

The module on the left is the "database", in figure 1, which can be continuously updated with relevant data in real time through the advantage of big data, and on the right is the "equipment library" and the "actual response". According to the related literature we find that Shanghai and Ningbo, which are close to Zhoushan, have large number of oil spill prevention facilities, while Zhoushan has much less compared with Ningbo and Shanghai. 


\section{Example of Simulation Case}

Currently, Zhoushan owns some vessels to deal with oil spill emergency. This paper will take the oil spill accident in the port of Ma'ao as a case. According to the above process, firstly, establish the hydrodynamic module through MIKE software, and then establish the oil spill module to simulate the oil spill situation in the port area of Ma'ao. The oil spill emergency is carried out for the relevant situation in the following figures (figure 3 and figure 4) [5].

According to the influence of tide, the oil spill situation within 12 hours after the occurrence of oil spill, the oil spill situation is shown in the following figure, figure 2 is the oil spill spreading situation under the static wind condition; Figure 3 is the oil spill spreading situation when the dominant wind direction is $4.8 \mathrm{~m} / \mathrm{s}$.

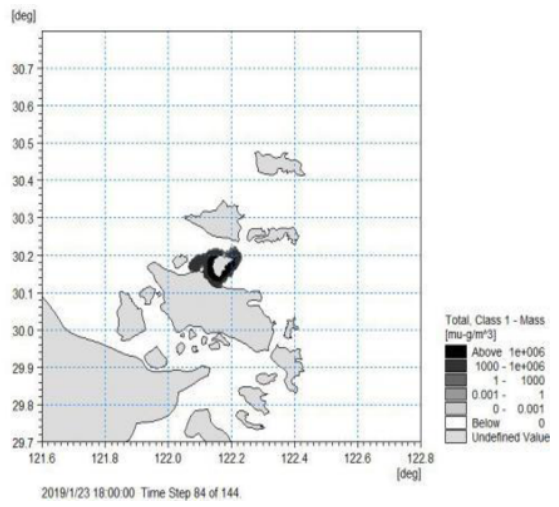

Figure 2. Oil spill dispersion under static wind condition in 12 hours.

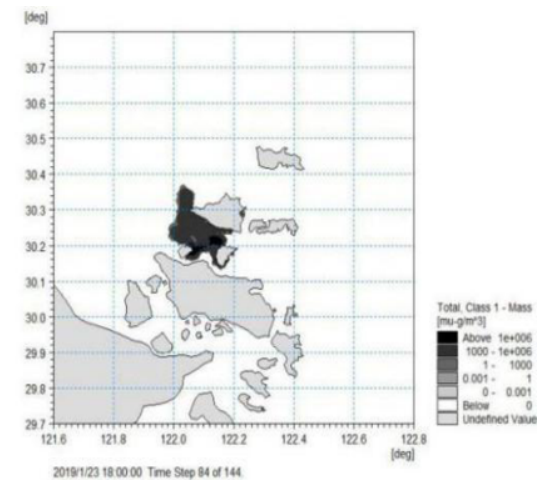

Figure 3. Oil spill dispersion under the main wind direction of $4.8 \mathrm{~m} / \mathrm{s}$ in 12 hours.

As shown in the figure above (figure 3 and figure 4), the darker color in the middle indicates a higher degree of oil spill impact, and the lighter color shows the lower degree of oil spill pollution. The darker color in the middlemost area is suitable location for rescue vessels to proceed relevant recovery treatment process. The outermost area can be treated with proper treatment agents. The best time to control the oil spill is within 12 hours after the spill occurs. If the oil spill situation can be received on time and the rescue vessels can be sent to the scene as soon as possible, the impact of the oil spill can be well controlled.

In geometry, the envelope of a certain family of curves is a curve that is tangent to every line of that family of curves at least at one point. This paper uses the outer envelope method which indicates that all points within the envelope can be reached in a given time. The figure 4 shows that several ports can be reached quickly, which are available from the envelope. The port distribution map is manually extracted according to the software of satellite remote sensing, and there might be not exact. The relevant zones covered by yellow, blue and red can be rushed to the scene for rescue faster if any port that owns rescue vessels is in the domain. The yellow part means that from the port to the oil spill location, the rescue vessels can arrive within 5 minutes. One of the ports in the map (i.e., the port of Ma'ao) can meet this conditions. The blue area indicates that the vessels can be reached within 10 minutes after the oil spill occurs. In 
addition to the port of Ma'ao, there is also the west port of Xiushan Island and Sanjiang port (near the port of Ma'ao) to meet the requirements. The red distinct indicates that rescue boats can be reached within 30 minutes. And the purple area describes that the vessels can be reached within 45 minutes.

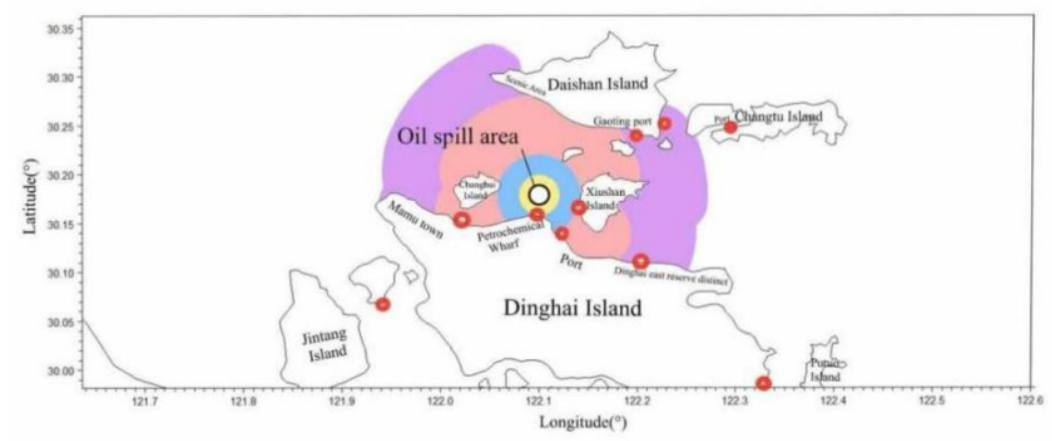

Figure 4. The envelope of the oil spill area arriving at different times.

Meanwhile, for the shoreline protection and related oil spill treatment, the geographical environment and structure of the shoreline need to be considered so that different containment and control measures can be selectively applied. If the oil spill occurs and the first response for treatment is missed, shoreline protection and oil spill treatment measures should be carried out on Xiushan Island, Dinghai Island, Daishan Island and other relevant islands. According to the modeling of MIKE's oil spill module, the shoreline of Xiushan is affected more seriously. If shoreline protection fails and spilled oil are attached to the shore, shoreline removal actions should be organized as soon as possible to restore the function of the polluted shoreline.

The paper recommended to use mechanical equipment or manual recovery, and regular monitoring is required if the recovery process leaves to the nature itself. For oilcontaining waste that cannot be reused, the treatment methods are mainly focused on ways of burial, incineration, biotechnological degradation, solidification and land blowing, etc. The scope of application of different treatment methods is different. However, he treatment of oily waste is expensive and time-consuming. Therefore, it is necessary to minimize the generation of oily waste that needs to be treated from the beginning [6].

\section{Conclusion and Outlook}

Chinese oil spill prevention and control system can be furtherly improved. This paper uses big data as a platform to build architecture of oil spill prevention system through neural network. Besides, author takes the oil spill accident in Zhoushan Ma'ao terminal as a research case, simulates the related oil spill situation with MIKE software, determines the area that is more seriously affected by the oil spill, and selects the one that can reach the oil spill area faster for oil spill treatment, applying the method of envelope port via this system. At the same time, the number of oil spill treatment equipments in the area and the dynamic monitoring of the oil spill spread area need to be highlighted, relevant protection of the shoreline is carried out when necessary, and 
different oil spill containment measures are selectively applied. This system both vertically and horizontally opens the doors for coordination and dispatchment, gives the most optimal scheme measures, and records the relevant data into the database for the optimization of the scheme, in case the oil spill occurs in the future. It can provide some guidance help in time, cost and personnel dispatching for future oil spill accidents or even other environmental accidents [7-10].

\section{References}

[1] Zhou WQ. Study of oil spill treatment on water surface. Petrochemical Technology. 2016; 23(004): 6364.

[2] Yang Z, Chen Z, Lee K, et al. Decision support tools for oil spill response (OSR-DSTs): Approaches, challenges, and future research perspectives. Marine Pollution Bulletin. 2021; 167(1): 112313.

[3] Davies AJ, Hope MJ. Bayesian inference-based environmental decision support systems for oil spill response strategy selection. Marine Pollution Bulletin. 2015; 96(1-2): 87-102.

[4] Li P, Cai Q, Lin W, et al. Offshore oil spill response practices and emerging challenges. Marine Pollution Bulletin. 2016; 110(1): 6-27.

[5] Dong J, Tang Z, Zeng H, et al. Numerical simulation study of oil diffusion at low tide near the port area of Ma'ao, Zhoushan. E3S Web of Conferences. 2021; 245(8):01035.

[6] Xu LL. Emergency treatment of marine oil spill pollution. Marine Information. 2011; 000(003): 17-19.

[7] Qiao B, Chu JCh, Zhao P, et al. Study on Preparation of offshore oil spill emergency plan. Journal of the Institute of Water Transport Science. 2000.

[8] Chen Y. Emergency treatment study on the pollution events of sudden marine oil spill. Environmental Science and Management. 2014; 39 (006): 27-30,63.

[9] Zhong Z, You F. Oil spill response planning with consideration of physicochemical evolution of the oil slick: A multiobjective optimization approach. Computers \& Chemical Engineering. 2011; 35(8): 16141630 .

[10] Pan HL, Wang ZG. Analysis of the emergency response and management technology of foreign offshore oil spill. Work Safety Science and Technology in China. 2010; (S1): 65-67. 